ISSN : 2550-0198

\title{
IPTEK BAGI MASYARAKAT (IbM): SEKOLAH TK MENGHADAPI MASALAH IMPLEMENTASI SAINS
}

\author{
Sri Fitria Retnawati ${ }^{1}$, Yeeri Badrun ${ }^{1}$, Edi Ismanto ${ }^{2}$ \\ ${ }^{1}$ Fakultas Mipa dan Kesehatan, Universitas Muhammadiyah Riau \\ ${ }^{2}$ FKIP, Universitas Muhammadiyah Riau \\ *Email: fitriretno@umri.ac.id
}

\begin{abstract}
Abstrak
Isu utama pendidikan anak di Indonesia adalah Etika, moral dan kepedulian terhadap kelestarian lingkungan. Secara khusus masalah dalam pendidikan Taman kanak-kanak khususnya di kota Pekanbaru tidak ada Pengembangan Materi Sains atau Porsi Pembelajaran sains yang sedikit, pengajaran etika moral, kearifan lokal dan lingkungan hidup masih pada ranah kognitif. Untuk menjawab pertanyaan tersebut UMRI telah bermitra dengan Taman kanak-kanak Negeri Pembina 1 (TKN 1) dan Taman kanak-kanak Swasta Tri Insani Permata (TK-TIP) yang sedang di Pekanbaru dalam kegiatan pengabdian Iptek bagi Masyarakat (IbM). Dalam program ini telah disusun kurikulum baru yang menggabungkan pengajaran sains dan menanamkan moral, kearifan lokal dan kepedulian terhadap lingkungan hidup. Luaran yang berhasil dihasilkan dari kegiatan ini tersedianya kurikulum baru yang mengintegrasikan pembelajaran moral, kearifan lokal dan lingkungan hidup dan menyediakan alat peraga pembelajaran saintifik bisa menggunakan modul dan VCD penggunaan alat, untuk masing-masing Taman kanakkanak mitra.
\end{abstract}

Kata kunci: sains, etika, moral, kearifan lokal, taman kanak-kanak, pendidikan.

\section{PENDAHULUAN}

\section{Analisis Situasi}

Mitra dalam usulan Iptek bagi Masyarakat ini adalah 2 (dua) Taman Kanak-kanak, yaitu TK Negeri Pembina 1 (TKN 1) Pekanbaru yang telah berdiri 80 tahun yang lalu dan TK Swasta Tri Insani Permata (TKTIP) yang didirikan tahun 2009. TKN-1 beralamat di Jl Sarwo Edi, Kecamatan Limapuluh Kota Pekanbaru dan TKN-1 beralamat di Jln Anggrek KM 2, Garuda Sakti Kecamatan Tampan Kota Pekanbaru. Kedua TK ini berada di wilayah yang sama dengan Universitas Muhammadiyah Riau yaitu di Kota Pekanbaru.
Isu utama pendidikan anak dan remaja di Indonesia adalah Etika moral dan kepedulian terhadap kelestarian lingkungan. Isu tersebut saat ini menjadi sorotan oleh publik. Berbagai media massa telah memberitakan bagaimana mengkhawatirkannya etika dan moral remaja Indonesia saat ini. Untuk itu media pembelajaran TK sudah harus dapat menanamkan nilai-nilai etika moral dan kepedulian lingkungan dengan pendekatan saintifik.

Pendekatan saintifik adalah proses pembelajaran yang dirancang sedemikian rupa agar peserta didik secara aktif membangun kompetensi sikap, pengetahuan, dan keterampilan melalui tahapan mengamati, 
mempertanyakan, mengumpulkan informasi, menalar, dan mengomunikasikan. Pembelajaran ini hendaknya dilakukan melalui kegiatan-kegiatan yang menarik, membangkitkan rasa ingin tahu, memotivasi anak untuk berfikir kritis dan menemukan hal-hal yang baru yang pada akhirnya akan memunculkan pemahaman. Semua proses ini haruslah berada di dalam koridor etika moral, kearifan lokal yang berlaku di daerah TK tersebut dan kepedulian terhadap lingkungan hidup.

Berdasarkan hal tersebut, pendidikan di TK sebagai pembinaan awal anak pra sekolah, harus diupayakan agar anak memiliki kesiapan dalam memasuki pendidikan lebih lanjut yang telah ditanamkan etika moral, kearifan lokal dan kepedulian terhadap lingkungan hidup. Dengan mengembangkan pembelajaran saintifik sejak dini akan menumbuhkan kretivitas dan kemampuan berfikir kritis yang semuanya akan bermanfaat bagi aktualisasi dan kesiapan anak untuk menghadapi perannya yang lebih luas dan kompleks pada masa yang akan datang.

\section{Permasalahan Mitra}

Sasaran program ini adalah Sekolah TK Negeri I Pekanbaru (TKN1) dan TK Tri Insani Permata (TK-TIP). Secara khusus permasalahan yang dihadapi oleh kedua TK tersebut adalah:

\section{TK Negeri I Pekanbaru}

TKN1 Pekanbaru merupakan TK Pembina milik pemerintah Provinsi
Riau yang telah berdiri sejak 80 tahun yang lalu. Sebagai sekolah Pembina yang telah berdiri lama, TKN1 Pekanbaru memiliki sarana dan prasarana yang cukup memadai. Sampai saat ini jumlah siswa yang aktif di TKN1 sebanyak 100 orang dengan 11 orang guru yang memiliki latar belakang pendidikan S1, S2, dan SMA.

Dari hasil wawancara dengan kepala sekolah TKN1 diperoleh gambaran bahwa masih perlu pelatihan bagi guru untuk lebih memahamkan isi materi, keilmuan serta wawasan terhadap sains, etika moral dan lingkungan hidup agar dapat mengembangkan pembelajaran saintifik untuk anak didiknya. Diharapkan dengan meningkatnya profesionalitas guru dibidang sains TKN1 dapat menjadi Pembina TK lainnya di Pekanbaru.

\section{TK Tri Insani Permata}

TK-TIP berdiri sejak tahun 2009, sampai saat ini jumlah siswa aktif di TK-TIP adalah sebanyak 50 siswa dengan jumlah guru sebanyak 6 orang. 5 dari 6 orang Guru di TK-TIP berlatar pendidikan $\mathrm{S} 1$ dengan bidang PAUD, ekonomi, Bahasa Inggris dan Pendidikan Luar Sekolah, sedangkan sisanya berlatar belakang pendidikan D2 PGSD. Dari segi ekonomi ratarata orang tua berasal dari keluarga menengah ke bawah.

Hasil wawancara dengan Kepala Sekolah TK-TIP diketahui bahwa sampai saat ini dari seluruh kurikulum yang di terapkan, hanya $10 \%$ yang memiliki muatan sains degan pendekatan pengajaran yang tidak berlandaskan saintifik, etika moral, kearifan lokal dan lingkungan 
ISSN : 2550-0198

hidup secara utuh. Ini disebabkan karena sekolah tidak memiliki guru yang kompeten di bidang-bidang tersebut. Materi yang diberikan ke siswa juga belum maksimal, masih berorientasi pada ranah kognitif belum sampai ke ranah afektif dan psikomotorik.

Selain itu TK-TIP memiliki keterbatasan sarana dan Prasarana serta dana untuk menunjang media pembelajaran saintifik. Ini dikarenakan media pembelajaran saintifik yang beredar di pasaran relatif mahal. Sehingga jika dikonfirmasi mengapa tidak menambah muatan sains dalam modul kurikulum permasalahannya adalah kekurangan peralatan dan kemampuan tenaga pengajar.

\section{Justifikasi Pengusul bersama Mitra dalam menentukan Persoalan Prioritas yang disepakati untuk diselesaikan selama pelaksanaan Program IbM.}

Berdasarkan permasalahan yang dihadapi oleh mitra tersebut, maka Universitas Muhammadiyah Riau (UMRI), sebagai satu-satunya perguruan tinggi swasta di Pekanbaru yang memiliki Fakultas MIPA merasa memiliki kesempatan dan tanggungjawab untuk membantu permasalahan yang dihadapi oleh mitra.

Dalam program ini disepakati untuk diadakan program antara lain:

1. Pengukuhan kerjasama (MoU) antara UMRI dengan Mitra

2. Penyusunan Kurikulum Sains berbasis etika, moral, kearifan lokal dan Lingkungan
3. Penyusunan Media Pembelajaran Sains berbasis etika, moral, kearifan lokal dan Lingkungan hidup

4. Pengadaan perlengkapan kebutuhan khusus untuk pelatihan/workshop

5. Pelatihan untuk guru TK

6. Pengawasan Pelaksanaan

\section{METODE}

\section{Tahapan Pelaksanaan Program}

Program IbM ini akan dilaksanakan selama 8 bulan di 2 Tempat, yaitu di TKN1, dan TK-TIP dengan dengan 5 (lima) tahapan kegiatan pokok. Rincian kegiatan ditampilkan pada tabel berikut.

I. Persiapan Program Pengukuhan Kerjasama (MoU) antara UMRI dengan Mitra

II. Idenfikasi Kurikulum lama dan penyusunan kurikulum baru

1. Workshop telaahan kurikulum berjalan

2. Penyusunan draf Kurikulum Sains berbasis etika, moral, kearifan lokal dan Lingkungan

3. Sosialisasi kurikulum baru dengan pembelajaran saintifik berbasiskan berbasis etika, moral, kearifan lokal dan Lingkungan

III. Pengadaan Sarana dan Prasarana Program

1. Penyusunan Media dan alat peraga pembelajaran Sains berbasis etika, moral, kearifan lokal dan Lingkungan

2. Pengadaan perlengkapan kebutuhan pelatihan/workshop

IV. Implementasi Program 
ISSN : 2550-0198

moral, kearifan lokal dan Lingkungan.

d. Identifikasi dan penyediaan media/alat perlengkapan pendukung media pembelajaran Sains berbasis etika, moral, kearifan lokal dan Lingkungan.

e. Melakukan pelatihan untuk guru TK untuk penggunaan media dan alat peraga pembelajaran

3. Pihak mitra bersedia untuk terlibat penuh dalam tahapan kegiatan program IbM. Bentuk partisipasi mitra adalah:

a. Menyediakan tempat pelaksanaan kegiatan beserta sarananya dalam pelaksanaan workshop dan pelatihan.

b. Mendatangkan guru-guru TK dalam pelaksanaan worskshop dan FGD

c. Mendatangkan guru-guru TK dalam pelaksanaan Pelatihan untuk guru TK untuk penggunaan media dan alat peraga pembelajaran Sains berbasis etika, moral, kearifan lokal dan Lingkungan hidup.

d. Bersedia diwawancarai atau mengisi angket dalam rangka pelaksanaan evaluasi keberlanjutan program.

Adapun uraian pelaksanaan kegiatan yang telah direncanakan di jelaskan sebagai berikut.

b. Identifikasi Kurikulum Lama dan Penyusunan Kurikulum Baru

Pelaksanaan identifikasi kurikulum lama dilakukan dengan cara mengumpulkan dokumendokumen kurikulum masing-masing TK yang telah digunakan selama ini (kurikulum terlampir). Dari pengumpulan kurikulum tersebut, dilakukan telaahan terhadap kurikulum bersama dengan tim internal. Selanjutnya dilakukan survei dan pengamatan pelaksanaan kegiatan pembelajaran di kelas. Dan kemudian diikuti dengan pelaksanaan workshop telaahan kurikulum bersama tim UMRI dan Mitra. Dari hasil kegiatan tersebut disimpul beberapa temuan sebagai berikut:

\section{A. TKN 1}

a. Kurikulum TKN-1 telah menggunakan kurikumlum K13,

b. Pelaksanaan pendidikan di TKN-1 telah menggunakan metode sentra.

c. TKN-1 telah melaksanakan pendidikan etika moral, kearifan local serta lingkungan.

d. Impelementasi Kurikulum K13 di TKN-1 yang berkaitan dengan hal sain belum dapat dilaksanakan secara utuh karena kekurangan SDM yang memahami secara utuh khususnya dengan pembelajaran Sains.

e. Telah ada guru yang spesifik yang kompetensinya sudah sesuai dengan kelas-kelas sentra.

f. Secara jumlah SDM juga masih dirasakan kurang dimana 1 orang guru menangai 25-30 murid setiap sentra.

B. TK-TIP

a. Kurikulum TK-TIP telah mengadposi Kurikulum K13, Pelaksanaan pendidikan di TKN-1 telah menggunakan metode area.

b. Impelementasi Kurikulum K13 di TK-TIP 1 namun belum dilaksanakan secara utuh 
ISSN : 2550-0198

karena kekuarangan sarana pendikan dan prasarana/ruangan/gedung pendidikan

c. Ketersediaan SDM Guru dan ruangan belum dapat memenuhi pedoman K13 yang menetapkan kelas sentra yang berbeda-beda

d. K13 memberikan kebebasan kepada guru untuk mengembangan kegiatan pembelajaran sesuai kompetensi inti dan kompetensi dasar yang ditetapkan dalam kurikulum tersebut. Namun ketersediaan SDM belum mampu untuk menyusun materi pembelajaran khususnya untuk pembelajaran sains.

Dari kesimpulan tersebut disusun beberap point rekomendasi yang berkaitan dengan penyempurnaan kurikulum masing-masing TK tersebut khususnya dalam pengembangan pembelajaran Sains berbasis etika, moral, kearifan lokal dan Lingkungan perubahan tersebut disampaikan dalam lampiran 1 Laporan ini.

Selanjutnya dengan telah tersusunnya usulan perbaikan kurikulum tersebut, kegiatan yang akan dilaksanakan selanjutnya pada tahapan ini adalah sosisalisasi kurikulum baru sekaligus penyemurnaan dari saran-saran yang masuk setelah pelaksanaan sosialisasi tersebut.

\section{c. PengadaanSarana Pembelajaran}

Untuk mendukung kegiatan pelaksanaan pembelajaran yang berkaitan dengan pengembangan Sains berbasis etika, moral, kearifan lokal dan Lingkungan terhadap murid TK, diadakan beberapa pengadaan sarana pembelajaran. Pengadaan sarana pebelajaran ini dilakukan sesuai dengan alternative media pembelajaran yang telah disusulkan dalam rekomendasi penempurnaan kurikulum TK. Daftar pengadaan selanjtunya didiskusikan dengan pihak mitra untuk menilai kesesuaian dan kebutuhan masing-masing mitra. Hasilnya disimpulkan daftar pengadaan saran pemebelajaran sebagai berikut

1. Pengadaan Proyektor untuk kebutuhan masing-masing TK.

2. Pengadaan video interaktif pembelajaran yang terdiri dari Materi:

a. Materi tentang Hewan

b. Materi Tentang Luar Angkasa

c. Materi Tentang Anggota Tubuh Manusia

d. Materi Tentang Fungsi Tubuh

e. Materi Tentang Binatang Laut

f. Materi Tentang Sains Kit

i. Panca indra

ii. Kesehatan

iii. Pengukuran iv. Suhu

g. Materi Tentang Alat Transportasi darat, laut dan udara.

\section{d. Sosialisasi Kurikulum}

Sosialisasi kurikulum baru dengan pembelajaran saintifik berbasiskan berbasis etika, moral, kearifan lokal dan Lingkungan.

Kegiatan sosialisasi ini dilakukan kembali melalui Metode FGD, yang merupakan kegiatan diskusi terfokus dari suatu grup guru-guru TK Mitra. 
ISSN : 2550-0198

Metode ini digunakan untuk menyampaikan kurikulum TK yang telah disusu berdasarkan model pengajaran saintifik berbasiskan etika, moral, kearifan lokal dan Lingkungan. Hasil yang ingin dicapai dari kegiatan ini adalah adanya respon balik dan pemahaman para guru terhadap penyempurnaan kurikulum yang telah dilakukan.

\section{e. Pelatihan Guru TK}

Pelatihan untuk guru TK untuk penggunaan media dan alat peraga pembelajaran Sains berbasis etika, moral, kearifan lokal dan Lingkungan. Kegiatan ini akan dilaksanakan melalui pengembangan Tindakan keterampilan baru atau pendekatan baru dan diterapkan langsung serta dikaji hasil evaluasinya. Penerapan Metode Tindakan dilakukan oleh para partisipan/mitra dalam situasi-situasi yang diinginkan untuk memperbaiki praktek pengajaran yang akan dilakukan yaitu pengajaran/pendidikan berorientasi saintifik berbasis etika moral, kearifan lokal dan lingkungan hidup terhadap murid TK. Terdapat dua esensi metode tindakan ini yaitu perbaikan dan keterlibatan. Hal ini mengarahkan tujuan kegiatan ini ke dalam tiga area yaitu: (1) Untuk memperbaiki teknik pengajaran; (2) Untuk pengembangan profesional dalam arti meningkatkan pemahaman/kemampuan para guru terhadap praktek pengajaran yang ingin dilaksanakannya; (3) Untuk mengadakan dan atau memperbaiki alat peraga dan sarana di mana pengajaran tersebut dilaksanakan.

\section{SIMPULAN}

1. Kedua TK yang menjadi mitra masih membutuhkan bantuan dalam peningkatan kualitas pengajaran sains, etika, moral, keraifan lokal dan lingkungan hidup.

2. UMRI telah menelaah kurikulum Tk Mitra dan mengembangkan pengajaran sains, etika, moral, keraifan lokal dan lingkungan hidup yang dibutuhkan mitra

3. Kurikulum yang telah disusun bersama UMRI dan Tk Mitra telah melalui sosialisi dan FGD dengan tenaga pendidik di Tk Mitra.

4. Berbagai media pembelajaran yang mendukung pengajaran sains, etika, moral, keraifan lokal dan lingkungan hidup telah diserahkan kepada Tk Mitra sebagai bagian program bantuan peningkatan kualitas pengajaran sains, etika, moral, keraifan lokal dan lingkungan hidup

5. Hasil dari pengabdian ini berupa 2 paket rancangan kurikulum untuk kompetensi sains, media pembelajaran sains dan pelatihan penggunaan media sains.

6. Kendala dari pelaksanaan kegiatan ini adalah pengaturan jadwal pelaksanaan kegiatan.

\section{Saran}

1. Perlu dikembangkan media sains yang lebih lengkap dengan topik yang lebih beragam sesuai kearifan lokal di Riau

2. Perlu dilakukan evaluasi materi pembelajaran pengajaran sains, etika, moral, kearifan lokal dan lingkungan hidup yang telah disampaikan. 
ISSN : 2550-0198

\section{UCAPAN TERIMAKASIH}

Terima kasih disampaikan kepada Direktorat Riset dan Pengabdian kepada Masyarakat, Direktorat Jenderal Penguatan Riset dan Pengembangan, Kementerian Riset, Teknologi dan Pendidikan Tinggi sebagai penyandang dana pelaksanaan kegiatan Iptek bagi Masyarakat (IbM) ini tahun anggaran tahun 2017.

Terimakasih juga diucapkan kepada Tk Pembina Negeri 1 Pekanbaru dan Tk Tri Insani Permata sebagai Mitra Pelaksanaan program IbM ini

\section{DAFTAR PUSTAKA}

[1] Abdullah Idi. 2007. Pengembangan Kurikulum. Teori \& Praktek. Jogjakarta : Ar-Ruzz Media.

[2] Direktorat Pembinaan Pendidikan Anak Usia Dini Direktorat Jenderal Pendidikan Anak Usia Dini Dan Pendidikan Masyarakat, 2015. Norma, Standar, Prosedur, Dan Kriteria Petunjuk Teknis Penyelenggaraan Taman
Kanak-Kanak. Kementerian Pendidikan Dan Kebudayaan.

[3] Direktorat Riset dan Pengabdian kepada Masyarakat, Direktorat Jenderal Penguatan Riset dan Pengembangan, 2016. Panduan Pelaksanaan Penelitian dan Pengabdian Kepada Masyarakat. Kementerian Riset, Teknologi dan Pendidikan Tinggi.

[4] Essa, Eva L. 2003. Introduction To Earlychildhood Education. Canada : Thompson Delmar Learning.

[5] Getstwicki, Carol. 2007. Developmentally Appropriate Practice. Curriculum and Development In Early Education. Canada : Thomson Delmar Learning..

[6] Permendikbud 137 tahun 2014 tentang Standar Nasional PAUD.

[7] Permendikbud No. 146 tahun 2014 tentang Kuriulum 2013 PAUD

[8] Solehuddin, M. (2000). Konsep Dasar Pendidikan Pra-sekolah. Bandung: Fakultas Ilmu Pendidikan UPI.. 